\title{
Impacts of Volunteer Tourism on the Orphans
}

\author{
Dr. Raweewan Proyrungroj \\ Woosong University, Daejeon, South Korea
}

\begin{abstract}
This study investigated the impacts of volunteer tourism on the orphans in Thailand from the perception of the staff members of the host organizations. An interpretive paradigm utilizing qualitative research was employed. A combination of semi-structured interviews and participant observation were used to collect the data. Key informants included twenty-four staff members of the orphanages in Thailand. The findings of the research suggest that the staff members of the orphanages believed that volunteer tourism had provided both positive and negative impacts on the children. The positive impacts included: an opportunity for the orphans to learn English; familiarity with Western people and culture; and having good role models in terms of sharing. In terms of the negative impacts, the respondents believed that the children usually suffered from sadness when the volunteer tourists left the orphanage because they had established a bond with these volunteer tourists. However, they believed that this did not have a long-term effect on the development and the emotional and psychological health of the orphans because these children had been looked after and cared by the orphanage staff members who acted as their parents and always stayed with them.
\end{abstract}

Keywords: orphan volunteer tourism, orphans, volunteer tourists, positive impacts, negative impacts 